\title{
CERVICAL SPINE DISLOCATIONS WITH UNILATERAL FACET INTERLOCKING
}

\author{
By Dr. Ailie Key \\ Spinal Injuries Centre, Conradie Hospital, Capetown, S. Africa
}

\section{INTRODUCTION}

A SUREVY of 92 cases of cervical spine dislocations with unilateral facet interlocking admitted to the Spinal Unit in Cape Town during the period November 1963 to December 1973.

The statistics relating to the incidence, the cause of injury, the level of injury and the mortality are given. The clinical and radiological diagnosis, treatment and degree of neurological recovery are discussed.

\section{INCIDENCE}

During the period from November 1963 to December 1973, I333 new lesions were admitted to the Spinal Unit in Cape Town-mainly from the Cape Province alone. 525 cases were cervical orthopaedic lesions and of these 92 were dislocations with unilateral facet interlocking (Table I).

\section{TABLE I}

Case series

Total admissions 1963-I973

Cervical orthopaedic lesions

Dislocations with unilateral facet interlocking

1333
525
92

The incidence of cervical dislocations with unilateral facet interlocking was quoted to be extremely low by Braakman (1967) -one per two million people per year in the Netherlands based on a series of 37 cases from three clinics in the Netherlands.

Our figures indicate approximately twice that amount-one per million people per year at our Unit alone, that is excluding all those cases without any spinal cord damage treated elsewhere.

\section{CAUSES OF INJURIES}

Motor vehicle accidents were responsible for 53 of the injuries, involving drivers, passengers, pedestrians and cyclists. Falls which accounted for 20 of the cases were more often than not of a trivial nature, including one young male who merely tripped over a chair. The eight industrial accidents were mainly due to a 


\section{TABLE II}

Causes of injury

Motor vehicle accidents

Falls

Industrial accidents

Assault

Rugby

Diving

53
20
8
5
4
2

TABLE IV

Deaths

22

$\begin{array}{cc}\text { Reduced } & \text { Unreduced } \\ \text { I5 } & \text { I } 2 \\ 5 & -\end{array}$

TABLE III

Level of injury

Number of cases $\quad 92$

$\mathrm{C}_{3}-4$

$\mathrm{C} 4-5 \quad 37$

C5-6 32

C6-7 18

heavy object falling on to the base of the neck and shoulders of the injured, e.g. a sack of corn. The rest of the total were a few assaults, rugby and diving injuries (Table II).

\section{LEVEL OF INJURY}

The level of injury in this series was mainly in the lower cervical spine, confirming the findings of others (Braakman \& Vinken, 1967) with 69 cases (75 per cent) in the $\mathrm{C}_{4}-5$ and $\mathrm{C}_{5}-6$ regions (Table III).

\section{MORTALITY}

There were 22 deaths-I 8 within one month of injury, four within three to six months. A further nine deaths have been reported post-discharge (Table IV).

Of the 17 complete lesions there was one $\mathrm{C}_{3}-4$ lesion, six $\mathrm{C}_{4}-5$ lesions, nine C5-6 lesions, and two C6-7 lesions. Of the five incomplete lesions there were three $\mathrm{C}_{4}-5$ lesions, one $\mathrm{C}_{5}-6$ lesion and one C6-7 lesion.

Death in most cases was due to respiratory, and cardiac failure, there was one coronary thrombosis, one fulminating pyelonephritis and one iliac thrombosis.

\section{CLINICAL AND RADIOLOGICAL DIAGNOSIS}

Asymmetrical incomplete neurological lesions are often indicative of unilateral facet interlocking. The head is often held in a position of slight flexion and rotation to the side of the facet interlocking. This is said to be due to muscular spasm and not the interlocking (Braakman, 1967) but is nevertheless a useful diagnostic sign when present.

A definite diagnosis can only be made radiologically, where the features are very characteristic when recognised. During the first six-year period at our Unit 

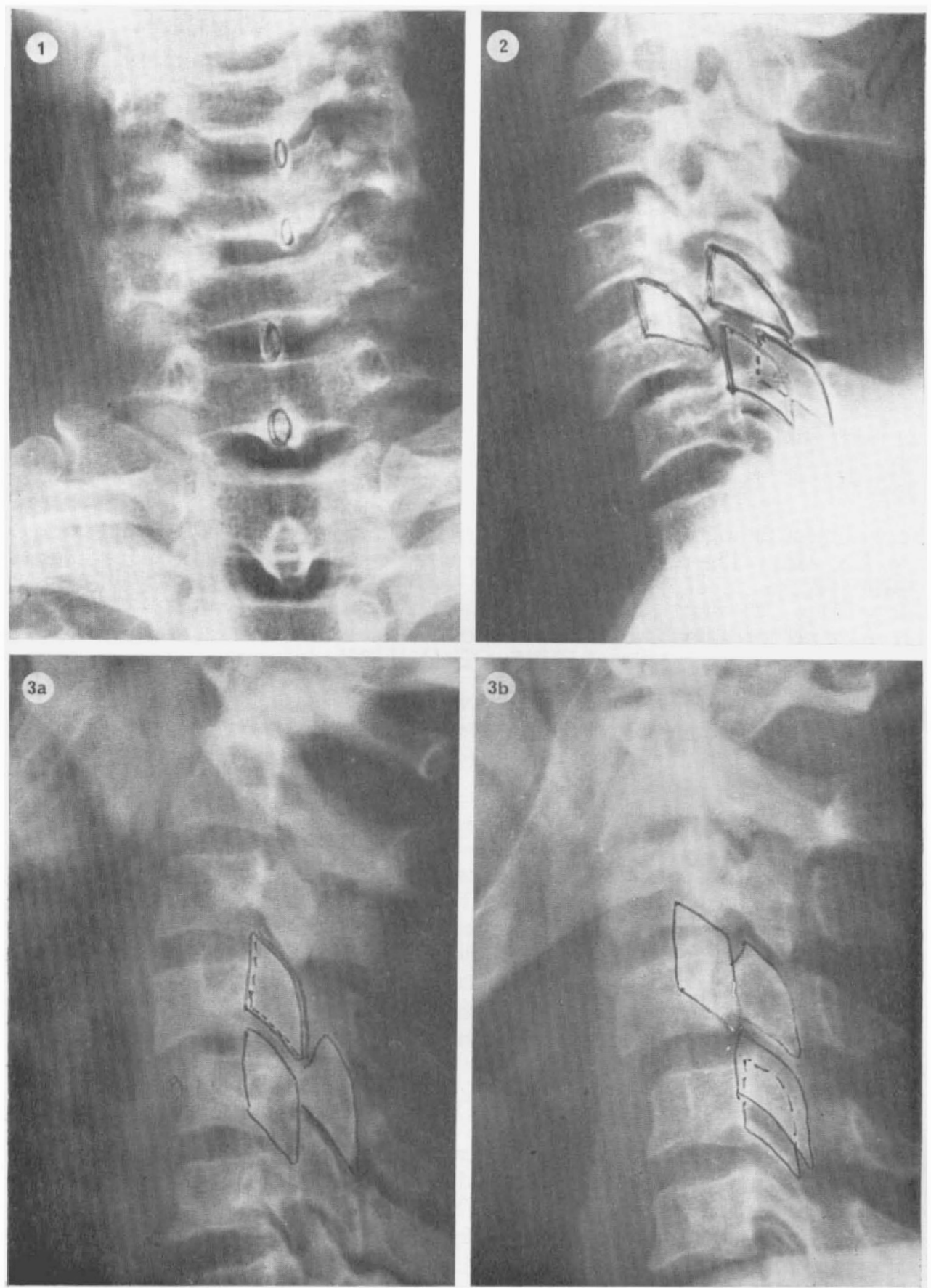

Figs. I, 2, 3a and $3 b$ 
many of these unilateral facet interlockings were missed and were labelled 'subluxations' due to our failure of recognition. It is surprising to note however how many of these reduced on what today would be considered inadequate therapy, namely Halter traction alone with five to seven lbs. with the neck in extension over a small cervical roll. Halter traction successfully reduced ten out of 14 cases during this period-a pleasing retrospective finding.

On the antero-posterior radiograph (fig. I) the spinous processes of the vertebrae above the dislocation are usually deviated from the midline to the side of the interlocking-not a constant feature but when present useful diagnostically.

On the lateral radiograph (fig. 2) the zygaophyseal joint on one side is displaced, evidenced by a 'bow-tie' appearance of the facets. This may be seen either above or below the site of the dislocation (fig. 3) depending on whether the true lateral projection is obtained above or below by the radiographer.

There is usually up to 50 per cent vertebral body shift or displacement present when only one facet is locked-over 50 per cent displacement is inevitably indicative of bilateral facet interlocking. There need not however be any or only minimal vertebrae body displacement with unilateral facet interlocking present (fig. 4). It is often in these cases, and in particular the C6-7 and $\mathrm{C}_{7}$ - $\mathrm{T}$ I regions where visualisation of the facets is often very difficult, that the diagnosis is often missed. We have found $10^{\circ}-20^{\circ}$ lateral oblique projections particularly useful to confirm or reject the diagnosis in cases with difficult to interpret lateral projection radiographs (fig. 4). Boylston from Houston Texas (1957) advocated oblique views in full flexion and extension rotating the head maximally on the shoulders in order to

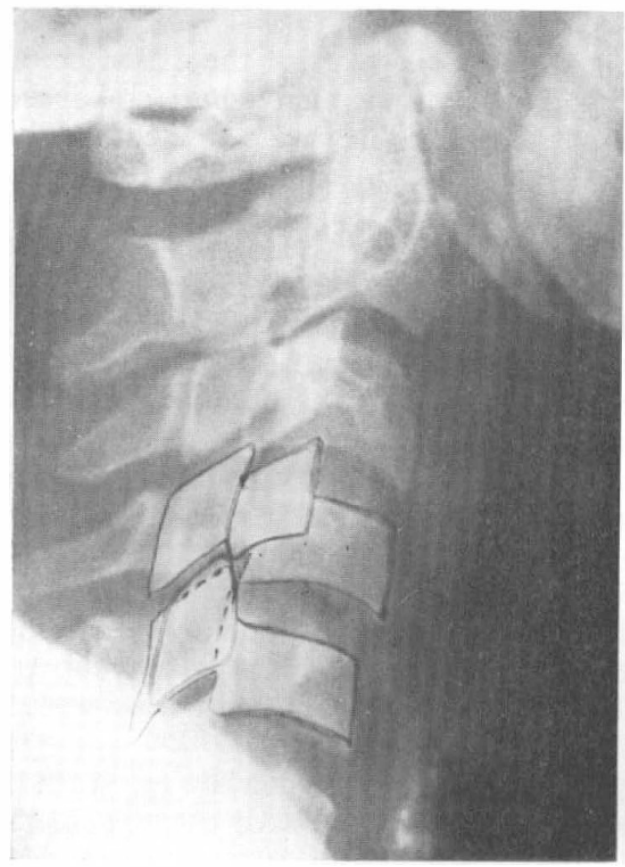

FIG. 4

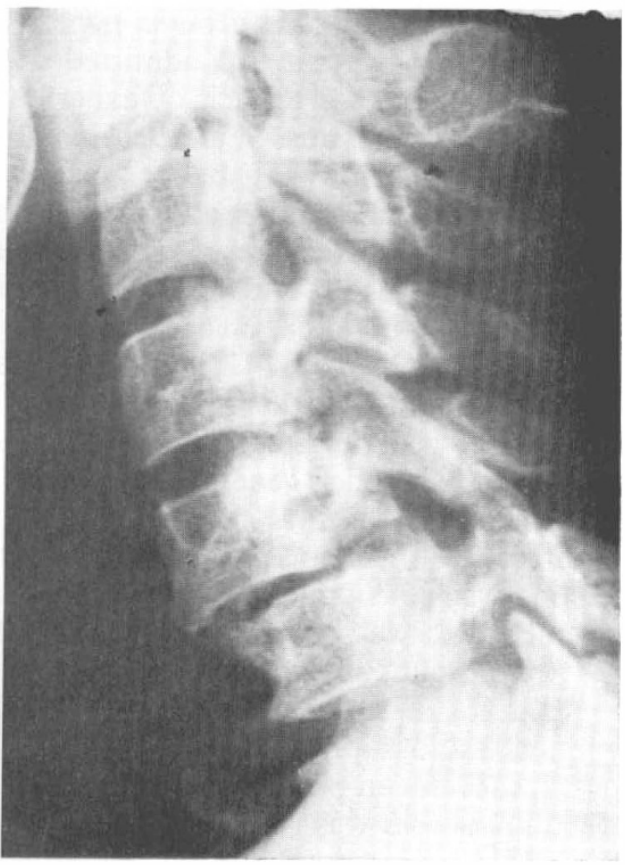

FIG. 5 


\section{TABLE V}

Treatment

\begin{tabular}{|c|c|c|c|c|c|c|}
\hline & \multirow{2}{*}{$1963-69$} & \multirow{2}{*}{$1970-72$} & \multirow{2}{*}{ I973 } & \multirow{2}{*}{ Total } & \multicolumn{2}{|c|}{ Reductions } \\
\hline & & & & & Achieved & Failed \\
\hline Postural & 5 & I & I & 7 & I & 6 \\
\hline Manual traction & 2 & - & - & 2 & 2 & - \\
\hline Halter traction & 14 & 2 & - & I6 & 12 & 4 \\
\hline Skull traction & 8 & 13 & 9 & 30 & 23 & 7 \\
\hline Halter M.V.A. & 3 & I & - & 4 & 4 & $-\cdots$ \\
\hline Skull and M.V.A. & 3 & 23 & 7 & 33 & 32 & I \\
\hline Total & 35 & 40 & I7 & 92 & 74 & I8 \\
\hline
\end{tabular}

detect hitherto undetected unilateral facet subluxations. The static $10^{\circ}-20^{\circ}$ lateral oblique projections are less hazardous and do demonstrate facet interlocking very well indeed, at all levels.

\section{TREATMENT}

For the purpose of discussion of treatment (Table V), I have divided this series into three distinct groups, namely:

I. Thirty-five patients admitted during the first six years of the existence of our unit, when due to lack of experience and recognition many unileteral facet interlockings were missed and treated as subluxations. They were treated mainly either posturally or with halter traction with the neck in extension; a few were treated with skull traction and six were manipulated.

2. Forty patients admitted during the following three years when the unilateral facet interlockings were recognised-our thanks go to Dr. D. Dall who in his M.Ch. thesis in I968 on our cervical injuries made this type of dislocation abundantly clear to us. These cases were treated mainly with Crutchfield skull caliper traction. If this failed to achieve reduction within I2-24 hours 'manipulation' under general anaesthesia was then carried out. I would like to stress that 'manipulation under general anaesthesia' as carried out at our unit should rather be termed 'increased traction under general anaesthesia with a relaxant and without endotracheal intubation'. However during this period the application of skull traction was not standardised throughout with regard, in particular, to the direction of pull which was initially done in slight flexion and latterly in a neutral position, and the amount of weight utilised was initially up to $60 \mathrm{lbs}$. and latterly up to $20 \mathrm{lbs}$. for a 12-24 hour period or up to $40 \mathrm{lbs}$. for a two to three hour period under frequent radiographic surveillance.

3. Seventeen patients admitted during the one year 1973 when the application of skull traction was standardised throughout as stated above with traction up to $20 \mathrm{lbs}$. or $40 \mathrm{lbs}$. in a neutral position. Towards the end of 1973 a new policy was adopted by our Orthopaedic consultant to commence a series of cases of 


\section{TABLE VI}

Neurological recovery

\begin{tabular}{|c|c|c|c|c|}
\hline \multirow[b]{2}{*}{ On admission } & & \multirow[b]{2}{*}{ I.S.Q. } & Reduced. & On discharge \\
\hline & & & Minimal recovery & Major recovery \\
\hline \multirow{4}{*}{$\begin{array}{l}\text { Complete } \\
\text { Sacral Sparing } \\
\text { Sensory Sparing } \\
\text { Sensory and motor } \\
\quad \text { sparing }\end{array}$} & IO & IO & - & - \\
\hline & I I & 6 & 2 & 3 \\
\hline & I4 & 2 & 6 & 6 \\
\hline & & & & \\
\hline \multirow[t]{2}{*}{ Total } & 54 & I8 & 9 & 27 \\
\hline & & & \multicolumn{2}{|c|}{ Unreduced. On discharge } \\
\hline On admission & & I.S.Q. & Minimal recovery & Major recovery \\
\hline Complete & 3 & 3 & - & - \\
\hline Sacral sparing & 5 & I & 3 & I \\
\hline $\begin{array}{l}\text { Sensory sparing } \\
\text { Sensory and motor }\end{array}$ & 一 & $\cdots$ & - & $-\cdots$ \\
\hline sparing & 8 & I & I & 6 \\
\hline Total & I6 & 5 & 4 & 7 \\
\hline
\end{tabular}

immediate closed reduction under general anaesthesia in all cervical dislocations admitted within 24 hours of injury without the initial period of skull traction. If this failed to effect satisfactory reduction it was to be followed immediately by open reduction and posterior spinal fusion. Two cases in this series were thus 'manipulated' successfully without prior skull traction, neither thus required open reduction. It is possible however that skull traction alone may have sufficed to achieve reduction in these two cases.

Of the total 74 cases successfully reduced, 38 (5I per cent) were reduced either posturally or by traction alone-manual, halter or skull (Rodgers of Boston (I96I) quotes a 90 per cent success rate with skull traction in all cervical injuries). Thirtysix were reduced successfully with 'manipulation' under general anaesthesia.

Of the 18 cases who failed to reduce, 17 were treated posturally or by traction alone and one manipulation under anaesthesia failed, due, it is felt, to a fractured facet preventing even manipulative reduction. Twelve of the $\mathrm{I} 8$ failed reductions however belong to the period of non-recognition $1963-69$, four were very poor anaesthetic risks and therefore 'manipulation' under general anaesthesia was not attempted, one was only diagnosed when a late spinal fusion for instability was done and the remaining one was the failed manipulation already referred to. 


\section{NEUROLOGICAL RECOVERY}

In this total series of 92 cases approximately two-thirds (62 cases) were incomplete neurological lesions and one-third (30 cases) were complete neurological lesions, on admission (Table VI).

Of the total 70 who were discharged, 54 were successfully reduced and 16 remained dislocated. Minimal neurological recovery has been assessed as sensory or sensory and motor return, the latter of a degree insufficient to allow reasonable ambulation out of a wheelchair without appliances and major neurological recovery as sensory and motor return sufficient to allow reasonable ambulation without appliances through to normality.

All I 3 cases who were initially complete neurological lesions remained complete. Of the 16 cases with initial sacral sparing only four cases (two in the reduced group and one in the unreduced group) showed major neurological recovery five cases (two reduced, three unreduced) showed minimal neurological recovery and the rest, seven cases (six reduced, one unreduced) remained ISQ. Fourteen cases with considerable initial sensory sparing but total motor loss, showed a greater tendency towards major or full recovery and those with initial sensory and motor sparing 27 cases (I9 reduced, eight unreduced). Twenty-four achieved major neurological recovery.

There were no cases that deteriorated neurologically either as a result of traction or 'increased traction under general anaesthesia with relaxants and without endotracheal intubation'.

\section{SUMMARY}

From this series it would appear that 17.5 per cent (92 cases from a series of 525) of all cervical lesions associated with spinal cord trauma are dislocations with unilateral facet interlocking. This type of dislocation is often missed but nevertheless with suitable radiographs the very characteristic radiographic appearances are well demonstrated. Two-thirds of these cases are initially incomplete neurological lesions which carry a good neurological prognosis directly proportional to the degree of initial neurological escape. A significant percentage reduce easily on traction alone-5I per cent of the entire series. Taking the year 1973, with I7 cases on a standardised regime of treatment and disregarding the two cases reduced by immediate manipulation under general anaesthesia, ten out of 15 (66 per cent) reduced easily on skull traction alone-possibly a more realistic figure.

\section{RÉSUMÉ}

Dans cette série, il semblerait que I7, 5 pour cent ( 92 cas sur une série de 525 ) de toutes les lésions cervicales associées à une lésion de la moelle épinière sont des tassements avec emboîtement unilatéral de facettes. Ce type de fracture par tassement est souvent omis; néanmoins, avec les radiographies appropriées, les phénomènes radiographiques très caractéristiques sont bien démontrés. Deux tiers des cas sont à l'origine des lésions neurologiques incomplètes qui comportent un bon pronostic neurologique directement proportionnel au degré d'issue neurologique initiale. Un pourcentage important se réduit facilement en faisant seulement appel à la traction-5I pour cent de toute la série Si l'on prend l'année I 973 avec I 7 cas en traitement normalisé et sans tenir compte de deux cas 
réduits par manipulation immédiate sous anesthésie générale-Io cas sur 15, c'est-à-dire 66 pour cent se sont réduits facilement par traction crânienne seulement-un chiffre sans doute plus réaliste.

\section{ZUSAMMENFASSUNG}

In 17.5 Prozent von 525 Luxationfrakturen wurde unilaterales Ineinanderhaken der Fazetten gefunden. Dieser Typ von Dislokationen wird oft übersehen. Zwei Drittel dieser Fälle sind initial inkomplette neurologische Läsionen mit guter Prognose, direkt proportional zum Grad des initialen Ausweichens des Rückenmarks. 5I Prozent der gesamten Serie werden mit Leichtigkeit durch Kopfzug reduziert. Zehn von fünfzehn Fälle (66 per cent), die I973 aufgenommen wurden, konnten durch Kopfzug allein leicht reduziert werden, zwei weitere Fälle in 1973 wurden durch sofortige Manipulation reduziert.

\section{REFERENCES}

BOYlston, BEDFORD, F. (196I). Oblique roentgenographic views of the cervical spine in flexion and extension. F. Bone E Foint Surg. 43B, 1032.

BRAakman, R., MAY \& VINKEN, P. J. (1967). Unilateral facet interlocking in the lower cervical spine. F. Bone E foint Surg. 49B, Number 2.

CRUTChField, W. G. (I954). Skeletal traction in treatment of injuries to the cervical spine. Fournal of the American Medical Association, 155, 29.

DALL, D. (I968). Injuries of the cervical spine. M.Ch. Thesis.

Evans, D. K. (I96I). Reduction of cervical dislocations. F. Bone E Foint Surg. 43B, 552. RoGERS, W. M. (I954). Fractures and dislocations of the cervical spine. An end-result study. F. Bone E Foint Surg. 39A, 34I. 